\title{
POLITIZANDO O DIGITAL: CONTRIBUIÇÕES PARA A CRÍTICA DAS RELAÇÕES ENTRE EDUCAÇÃO E TECNOLOGIAS
}

\author{
Gilson CRUZ JUNIOR
}

\begin{abstract}
RESUMO
Este ensaio tem como objetivo discutir o vínculo entre educação e tecnologias, fornecendo elementos para a crítica da educação digital, a partir da interlocução com o pensamento de Neil Selwyn. Como resultado, tem-se que o cerne do referido debate se encontra eivado por vícios explicativos e interpretativos que, no geral, derivam do determinismo tecnológico. Por fim, descrevem-se os princípios e os objetivos da sociologia digital, refletindo sobre o seu potencial analítico em relação às problemáticas que envolvem as apropriações escolares/educacionais das tecnologias de informação e comunicação.
\end{abstract}

PALAVRAS-CHAVE: Educação; Tecnologias digitais; Tecnologias educacionais; Sociologia digital; Neil Selwyn.

\section{POLITICIZING THE DIGITAL: CONTRIBUTIONS TO THE CRITIQUE OF THE RELATIONSHIP BETWEEN EDUCATION AND TECHNOLOGY}

\begin{abstract}
This essay aims to discuss the link between education and technologies, providing elements for a critique of digital education, based on the dialogue with Neil Selwyn's ideas. As a result, it points out that the core of the aforementioned debate is riddled with explanatory and interpretive vices that, in general, derive from technological determinism. Finally, it describes the principles and objectives of digital sociology, reflecting on its analytical potential in relation to the problems involving school/educational appropriations of information and communication technologies.
\end{abstract}

KEYWORDS: Education; Digital technologies; Educational technologies; Digital sociology; Neil Selwyn.

\section{POLITIZANDO LO DIGITAL: CONTRIBUCIONES A LA CRÍTICA DE LAS RELACIONES ENTRE LA EDUCACIÓN Y LAS TECNOLOGÍAS}

\section{RESUMEN}

Este ensayo tiene como objetivo discutir el vínculo entre educación y tecnologías, proporcionando elementos para una crítica de la educación digital, desde el diálogo con el pensamiento de Neil Selwyn. Como resultado, señala que el núcleo del debate antes mencionado está plagado de vicios explicativos e interpretativos que, en general, derivan del determinismo tecnológico. Finalmente, describe los principios y objetivos de la sociología digital, reflexionando sobre su potencial analítico en relación con los problemas relacionados con las apropiaciones escolares/educativas de las tecnologías de la información y la comunicación.

PALABRAS CLAVE: Educación; Tecnologías digitales; Tecnologías Educativas; Sociología digital; Neil Selwyn.

\footnotetext{
${ }^{\text {i }}$ Doutorado em Educação pela Universidade Federal de Santa Catarina. Professor adjunto no Instituto de Ciências da Educação da Universidade Federal do Oeste do Pará. E-mail: gijao05@ hotmail.com.
} 


\section{INTRODUÇÃO}

No decorrer das últimas décadas, as tecnologias digitais de informação e comunicação (TDICs) têm se constituído como uma das principais forças estruturantes da sociedade. Entre as questões despertadas pelo fenômeno no âmbito acadêmico, parte significativa se dedica às suas dimensões pedagógicas e ao seu potencial educativo. Frente às abundantes promessas de melhoria da qualidade dos processos de ensino-aprendizagem, uma das preocupações de maior destaque nesse campo é o hiato existente entre as potencialidades técnicas das TDICs e os ainda inconsistentes resultados de sua utilização - ou falta dela - em instituições e práticas educacionais formais. Cada vez mais, busca-se evidências sobre os obstáculos que têm impedido as tecnologias digitais de cumprirem sua suposta "missão" de reinventar os modos estabelecidos de fazer educação.

Para além de seus impactos diretos sobre as vidas de educadores, educandos e gestores, as TDICs também alimentam desafios de natureza teórica. Nesse domínio circulam conceitos e ferramentas intelectuais que cumprem papéis determinantes no modo como as tecnologias são definidas, caracterizadas e, por conseguinte, utilizadas em diferentes contextos de formação e investigação.

Mesmo tendo se consolidado como tópico permanente da agenda acadêmica, a relação entre tecnologias digitais e educação não tem sido pensada de forma suficientemente rigorosa. Esse é um entendimento compartilhado por um número crescente de pesquisadores e estudiosos, entre os quais se encontra Neil Selwyn: professor da Faculdade de Educação da Universidade de Monash, Austrália, além de autor de uma extensa lista de trabalhos acadêmicos no campo da educação digital. Dentre eles é possível observar a presença de discussões voltadas a aspectos como: as relações entre tecnologias digitais e sociedade; o uso de tecnologias em contextos educacionais; as tecnologias digitais e a exclusão social; as políticas públicas na "era digital"; e a sociologia digital da educação ${ }^{1}$. Mesmo acumulando publicações com mérito amplamente reconhecido, sua obra parece ainda não ter conquistado alcance significativo no contexto brasileiro.

Desse modo, o objetivo do presente ensaio é discutir as relações entre educação e tecnologias, na tentativa de reunir subsídios para a compreensão crítica desse vínculo, mediante o diálogo com o pensamento de Neil Selwyn. Não se trata de promover qualquer tipo de síntese integral da bibliografia do autor, haja vista as restrições inerentes ao texto aqui esboçado. Trata- 
se de reunir suas principais contribuições para o campo de investigação da educação na cultura digital, constituindo um convite e ao mesmo tempo uma porta de entrada para algumas de suas reflexões centrais. Para isso, o trabalho opera conforme o seguinte roteiro de discussão: 1) considerações sobre o potencial "transformativo" das tecnologias digitais; 2) fundamentos da sociologia digital; e 3) contribuições desta para a problemática educacional/escolar.

\section{UMA REVOLUÇÃO EM ANDAMENTO?}

Afinal, as tecnologias digitais estão realmente a transformar a educação? Ao contrário do que sugere sua formulação, a pergunta aciona temas que não podem ser enfrentados apenas por respostas categóricas e binárias, como "sim" e "não". Para além das réplicas possíveis, a indagação destoa pela própria possibilidade de semear a dúvida acerca da capacidade das tecnologias alterarem o estado e a essência atuais da educação. Em geral, computadores pessoais, tecnologias móveis, redes globais de comunicação digital e plataformas virtuais de sociabilidade parecem gozar de confiança inabalável da sociedade que, por seu turno, percebe seu protagonismo em mudanças e reformas macroestruturais que concorreram para a ascensão da aclamada "sociedade da informação". Diante dessa credibilidade, qual o sentido de colocar em dúvida a capacidade transformativa das TDICs em relação à educação do presente, uma vez que elas já viabilizaram mudanças decisivas em outros contextos tão ou ainda mais complexos?

Convém esclarecer que essa hesitação não busca reproduzir rixas maniqueístas envolvendo as tecnologias na educação, nem se apoia na simpatia por ideologias neoluditas.

Em meio a essa tensão, Neil Selwyn tem se dedicado à tarefa de compreender a lógica e a retórica subjacentes às tecnologias educacionais. Suas principais contribuições consistem em análises sobre ideias-chave no senso comum acadêmico relacionadas às TDICs, mais precisamente sobre representações e propostas correntes no campo da educação. Sob essa ótica, as tecnologias educacionais deixam de ser consideradas unicamente como recursos que encarnam potencialidades, promessas e inovação, apresentando-se como construções discursivas que povoam o imaginário social, ou seja, as TDICs são redesignadas como sistemas de ideias e valores que se materializam em saberes e fazeres no âmbito educacional, seja no plano das práticas educativas, seja no plano da produção científica e intelectual. Em diálogo com esse entendimento, as reflexões de Selwyn se dirigem ao que pensam e dizem os diferentes agentes que se dedicam ao estudo, à investigação, ao fomento e à operacionalização das 
tecnologias na educação (pesquisadores, intelectuais, gestores, comentadores e organizações transnacionais).

Particularmente, a relação entre as tecnologias e a transformação da educação foi abordada por Selwyn (2016) em Is technology good for education? (A tecnologia é boa para a educação?), livro em que se debruça sobre a ambivalência de diversas mudanças induzidas pela cultura digital. Ao indagar se as tecnologias são "boas" para educação, o autor esclarece que a sua intenção não é fornecer respostas definitivas, nem simplificar o debate. Reconhecendo o caráter "rude" e pouco sutil da pergunta, Selwyn observa que o debate da educação digital está repleto de questões similares, fato que, no seu entendimento, tem evidenciado as limitações e o empobrecimento das discussões sobre o futuro digital.

Além disso, Selwyn (2016) aponta o predomínio de termos e expressões oriundos de áreas como sistemas de informação e engenharia da computação, cuja linguagem tem servido de base para caracterizar diferentes aspectos da educação contemporânea. É sintomática a popularidade crescente de slogans como "Educação 2.0", "Educação 3.0", "Educação inteligente", "Educação conectada" e "Educação em rede", os quais estão em pleno alinhamento às propostas que visam submeter os processos educacionais do presente a "upgrades", "hackeamentos" e "reboots". Todas essas descrições "implicam uma recodificação e reescrita das regras da educação. Os objetivos da educação estão sendo renovados, com uma tecnologia digital atuando como catalisadora e facilitadora dessas mudanças" (SELWYN, 2016, p. 7, tradução livre). O autor afirma ainda que a educação tem contrabandeado não apenas vocábulos e metáforas de áreas afins com a computação e a informática, mas também seus esquemas explicativos e modelos de análise. Esse padrão pode ser reconhecido na popularidade do argumento de que as escolas e demais instituições de ensino representam um sistema "com defeito", uma máquina arcaica a ser "consertada" por meio da transposição de inovações técnicas exitosas em outros domínios e ramos de atividade.

De fato, a relevância das TDICs cresce no rastro do diagnóstico de que a educação contemporânea se encontra num crônico estado de crise. É uma leitura que extrapola preocupações restritas à didática e às práticas pedagógicas, alcançando esferas mais amplas do sistema educacional, como é o caso da dimensão política inerente às instituições de ensino.

Tornou-se comum a menção de que a educação está 'quebrada', ou que é um produto 'quebrado' e obsoleto de uma era passada [...] Tais descrições têm a intenção de transmitir uma sensação de má administração da educação por 
instituições monolíticas que são profundamente antidemocráticas e arcaicas. São organizações pesadas, em que a propriedade, o controle e o poder se concentram injustamente nas mãos das elites - sejam reitores e professores universitários, secretários e superintendentes municipais, professores efetivos e sindicatos. Como muitas grandes administrações e burocracias, essas instituições são consideradas insensíveis, incompetentes, não confiáveis, ingratas, egoístas e gananciosas. Como tal, são instituições que claramente "merecem" ser varridas do mapa (SELWYN, 2016, p. 11, tradução livre).

Apesar da legitimidade de algumas dessas críticas, essa linha de pensamento favorece o estabelecimento de um contexto no qual as propostas de transformação da educação, bem como seus respectivos promotores e facilitadores, estão inclinadas a serem valorizadas por si só e, por consequência, abraçadas de modo insuficientemente refletido, deixando em segundo plano a análise atenta das mudanças, dos efeitos colaterais e das eventuais contradições nos usos e nos projetos envolvendo as tecnologias na educação.

A mudança da educação por via das tecnologias também é abordada por Selwyn no livro Education and Technology: key issues and debates (Educação e tecnologia: questões-chave e debates). O trabalho discorre sobre os enunciados e vieses discursivos que discretamente povoam o campo das tecnologias educacionais, em especial, aqueles que induzem a leituras problemáticas e vícios argumentativos. Entre as principais fontes de equívoco, o autor dedica atenção especial ao determinismo tecnológico: princípio no qual as tecnologias são concebidas como uma força autorreferencial capaz de gerar, por si só, a mudança social, independentemente de variáveis políticas, econômicas, culturais e/ou subjetivas. Apesar de pouco confortáveis com essa descrição, professores, gestores e até mesmo pesquisadores frequentemente reproduzem o determinismo, ainda que em versões mais "suaves".

Por exemplo, uma maneira determinista de pensar sustenta a gama de afirmações populares de que várias formas de comunicação mediadas por computador causaram um declínio nos padrões tradicionais de alfabetização, ou que a internet leva a melhorias no aprendizado. Embora atraente para aqueles que querem construir explicações e modelos "científicos" delimitados, os perigos desse modo de pensar sobre o uso da tecnologia estão principalmente nas conclusões simplistas que induzem. Em particular, esse modo de pensar geralmente chega a conclusões que recomendam a superação de "barreiras" ou impedimentos dentro do contexto educacional imediato, de modo que os efeitos benéficos da tecnologia possam ser sentidos mais plenamente. Essa lógica é ilustrada na frequente "culpabilização" de professores ou instituições educacionais pelo fracasso das tecnologias digitais serem usadas "eficazmente" (SELWYN, 2011a, p. 34, tradução livre).

Elemento clandestino nos principais discursos sobre a educação digital, o determinismo tecnológico tem conferido credibilidade a expectativas e proposições pouco realistas em relação 
às TDICs. Mesmo quando estão fisicamente presentes nas instituições de ensino, as tecnologias não chegam a concretizar as principais promessas de transformação que semeiam. Assim constata Selwyn (2011a), a partir de uma reconstituição histórica em que revisitou as principais tecnologias de informação e comunicação surgidas e popularizadas ao longo dos séculos XIX e XX, precisamente, o cinema, o rádio, a televisão e o próprio computador. Ao analisar as narrativas dominantes no período de ascensão de cada um dos referidos meios, o autor observou que esses relatos são permeados por uma indistinção entre a maneira como as tecnologias são utilizadas e o modo como os pesquisadores e acadêmicos gostariam que elas fossem usadas. Com frequência, a educação se predispõe a abraçar as tecnologias como soluções técnicas "prontas" para problemas, em sua maioria, de natureza não tecnológica, por exemplo, a melhoria da qualidade do ensino. Como consequência, os estudos sobre o tema tendem se concentrar nos melhores usos e experiências com as tecnologias, em detrimento dos desvios e das manobras a elas associados, ignorando o fato de que as soluções tecnológicas costumam produzir resultados socioculturais incongruentes e, portanto, pouco previsíveis. Enquanto isso, seguem desprezados os resultados ineficazes e insustentáveis das tecnologias, como nos casos em que estas, por vezes, substituem ou criam novos problemas ao serem empregadas para resolver um problema anterior (SELWYN, 2017). Investigações influenciadas pelo determinismo tecnológico frequentemente confinam pesquisadores na função de tão somente identificar os obstáculos e entraves que se opõem à "marcha do progresso", incumbindo-os de mapear os fatores que impedem as TDICs de exercerem sua suposta vocação revolucionária. Por esse motivo, é difícil reconhecer os impactos reais de uma dada tecnologia sem o distanciamento histórico adequado, uma vez que cada invenção tecnológica, como explica Selwyn, costuma repetir um ciclo de implementação composto pelas etapas do hype (entusiasmo exagerado), das ações concretas e, finalmente, da decepção.

A história nos lembra que as soluções técnicas tendem a produzir resultados desiguais - muito raramente gerando os mesmos resultados para toda a população e muitas vezes apenas substituindo um problema social por outro. Mesmo que uma tecnologia seja vista como "eficaz", pode ser muito difícil entender por quê, especialmente quando a aplicação dessa tecnologia foi acompanhada por outras intervenções não tecnológicas. Muitas vezes, soluções técnicas tratam apenas das manifestações superficiais de um problema e não de suas raízes. De fato, os problemas sociais da educação são quantitativa e qualitativamente diferentes da maioria dos problemas técnicos da educação. Eles tendem a ser menos específicos, com muitas causas diferentes e não operam dentro de um sistema fechado como muitos problemas tecnológicos. Em suma, não devemos supor que as questões sociais 
que envolvem a educação são facilmente "solucionáveis" pela tecnologia (SELWYN, 2011a, p. 33, tradução livre).

Vale ressaltar que o determinismo tecnológico é uma preocupação em ascensão no âmbito das ciências humanas e sociais, sendo compartilhada por diversos intelectuais e pesquisadores no campo da cultura digital. Isto posto, não surpreende o fato dessa inquietação estar associada a múltiplas iniciativas que, mesmo dotadas de nuances, mantêm-se alinhadas ao anseio de evidenciar abordagens essencialistas e mecanicistas das TDICs. Ao refletir sobre a relevância de uma educação para as mídias, David Buckingham (2012) toma de empréstimo a noção de "ideologia californiana", a qual descreve como "uma espécie de libertarianismo cibernético populista que afirma que, de algum modo, as pessoas comuns ganharão poder por meio da tecnologia e que as mídias digitais serão inerentemente emancipadoras e contraculturais" (p. 25). Trata-se de uma modalidade wishful thinking que associa a presença e o uso de TDICs a consequências políticas, sociais e cognitivas intrinsecamente benéficas. Outro exemplo vem de Evgeny Morozov (2013), no livro To save everything, click here (Para salvar tudo, clique aqui), em que o autor relata casos que exemplificam o "solucionismo tecnológico", isto é, a convicção irracional de que as tecnologias representam um elixir capaz de aniquilar problemas sociais que, em sua maioria, não foram resolvidos pelo estado ou qualquer outra instituição. De modo geral, as críticas de Selwyn, Buckingham e Morozov convergem como tentativas de denunciar a hegemonia de uma visão romântica e, por consequência, estreita das tecnologias e de seus desdobramentos em diferentes áreas.

No âmbito educacional, o determinismo é uma força que está no âmago dos principais discursos existentes sobre as mídias e tecnologias. Por esses sistemas de pensamento, circulam argumentos, enunciados e valores responsáveis por dar legitimidade à integração das TDICs às situações de ensino-aprendizagem. Mesmo não sendo premissas de fácil identificação, Selwyn (2011a) reúne algumas das principais justificativas em prol da incorporação de tecnologias à educação. Estas foram classificadas como "imperativos" e divididas em dois grupos distintos, a saber: 1) os imperativos externos ao campo educacional; e 2) os imperativos internos à educação.

No primeiro eixo, o discurso em favor da inserção das tecnologias em contextos de ensino evoca macrotransformações econômicas e sociais normalmente resumidas em slogans como a "sociedade do conhecimento". Trata-se de uma realidade impulsionada por diferentes fatores, dentre os quais se encontram a ascensão de modos de produção pós-fordistas, a 
centralidade do trabalho imaterial e o fortalecimento de economias centradas em processos e mercadorias de natureza informacional. Nesse cenário, projetos formativos concernidos em tecnologias digitais são vistos como respostas às demandas emergentes no mundo do trabalho, no sentido de um investimento no desenvolvimento de competências essenciais aos indivíduos do século XXI. Em contrapartida, é comum que essa linha de raciocínio se restrinja a um conjunto de afirmações vagas e a jargões pouco elaborados, que, ainda assim, raramente são submetidos a uma leitura mais criteriosa. Entre eles, figuram assertivas que destacam transformações sociais recentes no âmbito da cultura, além da consequente mudança no perfil da clientela atendida pelas instituições de ensino - agora caracterizada por rótulos como nativos digitais, geração Z e homo zappiens. Nesse contexto, o papel das escolas e da própria educação é transparente: adaptar-se a essas mudanças, promovendo as readequações necessárias em suas práticas e estruturas.

Em outro viés, os imperativos internos à educação aliada às TDICs compõem um mosaico relativamente variado de pressupostos. Para além do lugar comum envolvendo a "melhoria" dos processos de ensino-aprendizagem, esse mote abrange argumentos nos quais as tecnologias cumprem (ou podem vir a cumprir) funções como: ajudar a promover abordagens pedagógicas ativas, construtivistas e centradas no aluno; ampliar o repertório didático dos professores; proporcionar ferramentas inteligentes de gestão e avaliação da aprendizagem; aumentar a eficiência organizacional das instituições de ensino, mediante a implementação de sistemas computacionais de administração baseados em recursos digitais; e contribuir para a democratização da educação por meio da oferta de cursos e modalidades de ensino acessíveis e de menor custo, como a educação a distância. Mesmo incompleto, o quadro reúne justificativas eloquentes que acionam tanto aspectos relativos às práticas pedagógicas nas salas de aula, quanto os próprios propósitos dos sistemas institucionais de ensino (QUADRO 1).

Quadro 1 - Imperativos externos e internos à educação

\begin{tabular}{|c|c|}
\hline \multicolumn{2}{|c|}{ IMPERATIVOS PARA INTEGRAÇÃO DE TDICs À EDUCAÇÃO } \\
\hline EXTERNOS À EDUCAÇÃO & INTERNOS À EDỦCAÇÃO \\
\hline $\begin{array}{l}\text { - "Modernizar" as instituições de ensino, } \\
\text { aproximando-as dos modos de vida } \\
\text { contemporâneos; } \\
\text { • Desenvolver competências básicas à } \\
\text { força de trabalho da era pós-industrial e da } \\
\text { sociedade da informação; } \\
\text { - Formar cidadãos aptos à participação } \\
\text { social e política na sociedade digital; }\end{array}$ & $\begin{array}{l}\text { - } \quad \text { Explorar os benefícios cognitivos dos } \\
\text { recursos digitais; } \\
\text { - } \quad \text { Promover processos de ensino- } \\
\text { aprendizagem centrados no educando; } \\
\text { - Auxiliar o trabalho dos professores tanto } \\
\text { no plano didático, quanto no âmbito da gestão e } \\
\text { avaliação da aprendizagem; }\end{array}$ \\
\hline
\end{tabular}


- Dialogar com o perfil sociocultural das novas gerações ("nativos digitais", "geração z" e "millenials").
Aprimorar a eficiência organizacional das instituições de ensino a partir de modelos de gestão e administração baseados em tecnologias e dados computacionais;

- Democratizar o acesso à educação mediante modalidades e sistemas de ensino sustentados pela comunicação digital.

Fonte: Autor, adaptado de Selwyn (2011a).

Por outro lado, ao servirem de inspiração e argumento para ações concretas, esses imperativos costumam revelar a natureza dúbia de seus impactos sobre a educação. Ao refletir sobre os principais benefícios advindos da integração das TDICs à educação, Selwyn (2016) pontua consequências pouco evidentes desse movimento e descreve como elas também podem originar preocupações capazes de ofuscar o clima de euforia que paira sobre a educação digital.

Um dos argumentos examinados é o de que as tecnologias atuam como vetores de democratização, favorecendo o surgimento e o fortalecimento de formas mais justas e igualitárias de educação. A despeito da complexidade de conceitos como "justiça" e "igualdade", essa assertiva se baseia no reconhecimento do mérito de modalidades educativas digitais emergentes no que diz respeito à redução de barreiras de acesso e ampliação da participação de grupos social e economicamente periféricos. Educação aberta (open education), $\mathrm{MOOCs}^{2}$ e a já mencionada educação a distância são apenas alguns dos segmentos responsáveis pelo aumento significativo na oferta de oportunidades formativas em rede, disponibilizando um volume crescente de cursos a preços acessíveis, ou mesmo gratuitos. Entretanto, apesar de contribuírem para a redução de disparidades históricas, esses avanços estão longe de representar uma democratização definitiva, visto que esse processo não se reduz às questões relativas ao acesso à educação, abrangendo também as condições de permanência e êxito em diferentes percursos formativos (SELWYN, 2016; SELWYN; FACER, 2013). Embora haja uma oferta global crescente de cursos on-line, esses ainda apresentam obstáculos que impedem a sua apropriação irrestrita, como o requisito de proficiência em línguas estrangeiras, além da posse de níveis razoáveis de alfabetização digital. Essas e outras competências indispensáveis costumam ser mais difundidas entre grupos com os maiores níveis de escolaridade e instrução, sobretudo nas classes com maior poder aquisitivo.

Em geral, observações assim sugerem que, quando enquadrados sob uma ótica determinista, os benefícios das tecnologias para a educação por vezes camuflam adversidades e efeitos colaterais que, em muitos casos, demonstram a inoperância das TDICs em relação à superação de problemas sociais e educacionais sistêmicos. 
Encarar essas consequências não significa negar a aptidão das tecnologias como forças indutoras de transformações na educação. Por outro lado, apesar de altamente difundido, esse pressuposto nem sempre vem acompanhado do esforço de discernir mudanças genuinamente estruturantes daquelas que representam tão somente uma nova roupagem para práticas e modos de organização tradicionais. Do mesmo modo, a crença de que as tecnologias são "boas" para a educação constantemente ignora a natureza política dessa articulação. Trata-se de uma tendência que sustenta a miopia em relação às normatividades implícitas nos discursos sobre a educação digital, contribuindo para a naturalização dos significados e das funções dominantes do conhecimento, dos professores, dos educandos e das próprias instituições de ensino, ainda que esses e tantos outros componentes vitais da atividade educacional sejam objeto de permanente debate e contestação. Em última análise, essa condição impõe a necessidade de admitir que o "bem" efetuado pelo digital nunca é absoluto, mas sempre relativo - um "bem" sob uma perspectiva particular e a partir de interesses específicos.

\section{REENQUADRANDO AS TECNOLOGIAS A PARTIR DA SOCIOLOGIA DIGITAL}

A superação de perspectivas deterministas e seus desdobramentos no âmbito das discussões sobre educação e tecnologias depende da busca e da construção de aportes teóricos adequados a esse desafio. Nesse contexto, a sociologia digital surge como uma das respostas à necessidade de amadurecer as bases da crítica em relação à sociedade da informação. Evidentemente, o status de nova ramificação no âmbito da sociologia ainda não está imune à desconfiança. Pairam sobre ela, ainda, dúvidas acerca de seu exato grau de ruptura com os estudos realizados em vertentes já estabelecidas das ciências humanas e sociais. Diante das suspeitas de modismo dirigidas ao referido campo, é conveniente indagar: a que exatamente se refere o "digital" da sociologia digital?

Várias explicações são formuladas na tentativa de demonstrar o caráter paradigmático das tecnologias digitais para a pesquisa social. Uma delas vem de Noortje Marres (2016), para quem o digital corresponde a uma maneira radicalmente nova de compreender a sociedade que não emergiu apenas de sociólogos, configurando-se como um amplo movimento de cunho interdisciplinar e operando tanto por intermédio de esforços acadêmicos quanto de debates públicos. Para ela, o digital remete a, pelos menos, três significados distintos: 1) tópicos e objetos para análise sociológica; 2) instrumentos e metodologias para a pesquisa social; e 3) plataformas para envolver e interagir com o público da sociologia. Cada um deles traz 
implicações específicas para as conotações assumidas pela sociologia digital em termos teóricos e práticos. Por isso, a autora esclarece que não é oportuno investir em definições excessivamente rígidas e universalizantes, já que o digital representa um domínio em constante mudança e complexificação.

Essa questão também foi abordada por Selwyn (2019) em What is Digital Sociology? (O que é sociologia digital?), livro em que esboça considerações introdutórias sobre o tema. De início, admite que a sociologia digital não consiste num movimento inteiramente novo, na medida em que vários sociólogos ${ }^{3}$ já realizaram trabalhos plenamente compatíveis com a disciplina antes mesmo que essa fosse formalmente fundada. Todavia, também chama atenção para a urgência de dar sentido à "sociedade digital", delineando táticas de interpelação compatíveis com a dimensão inerentemente digital assumida pelas formações sociais em decorrência da popularização de dispositivos computacionais em rede, sem com isso ignorar as diferenças e as desigualdades de uso e acesso que persistem nessa nova conjuntura. Além disso, explica que a sociedade contemporânea é cada vez mais organizada e administrada por meio de sistemas, serviços e aplicações digitais, demonstrando sua centralidade na mediação e regulação de atividades sociais essenciais, como o exercício da cidadania e demais formas de participação cultural e política.

Em linhas gerais, a sociologia digital pode ser considerada

[...] um chamado para a adoção de uma abordagem 'digital' deliberada e proativa em relação a todos os aspectos do trabalho sociológico. Isso envolve escrever e pesquisar os aspectos da vida social que também são de natureza digital. Por sua vez, isso implica questionar a relevância de métodos e teorias sociais familiares das eras 'pré-digitais', enquanto também se esforça para desenvolver novas formas de indagação, pensamento e conhecimento. Isso também significa buscar formas de comunicação e interação acadêmica digitalmente em rede que sejam abertamente acessíveis, compartilhadas e reconfiguradas (SELWYN, 2019, p.2, tradução livre).

Mesmo se tratando de uma disciplina em processo de afirmação, a sociologia digital já delineia os contornos de uma vertente voltada à educação. Na esteira do restante da sociedade, as instituições de ensino têm buscado estratégias para compreender o seu lugar em meio aos novos cenários, sociabilidades e fenômenos inaugurados pela cultura digital. Num ensaio direcionado à questão, Selwyn et al. (2016) discorrem em favor de uma sociologia digital da escola, argumentando sobre como as tecnologias digitais atualmente representam um atributo integral da educação institucional. Trata-se de uma realidade que se materializa na forma de 
fenômenos variados, como a crescente presença de dispositivos com acesso à rede nas instituições de ensino, a popularização de formas de trabalho pedagógico virtual, além da multiplicação de softwares e plataformas on-line voltadas à administração de escolas e universidades.

Em linhas gerais, a sociologia digital da escola se apresenta como uma alternativa para o estudo crítico do digital no contexto da escolarização, constituindo um "lar adequado" para investigações que há aproximadamente 30 anos ocorrem de maneira dispersa (SELWYN et al., 2016, p.147). Além disso, busca preencher lacunas observadas nos trabalhos provisoriamente alojados em disciplinas já constituídas. De um lado, a sociologia da educação não tem demonstrado interesse significativo na sociedade digital, além de apresentar carências em termos de conhecimento técnico para analisar os temas nesse domínio. De outro, os new media studies que, apesar de dedicarem atenção às questões da educação, são tomados por uma tônica tecnofílica e, por consequência, suscetível à acriticidade.

A sociologia digital da escola também visa contribuir com a pluralização do debate sobre educação e tecnologias, colocando em xeque a hegemonia de enfoques utilitaristas e exclusivamente centrados em temas inscritos nos âmbitos da didática e da pedagogia.

A conjectura para uma sociologia coordenada e abrangente das escolas e da tecnologia é mais urgente do que nunca - especialmente considerando o persistente escopo limitado da maioria das pesquisas sobre escolas e tecnologias. A maior parte do trabalho acadêmico sobre esse tema nos últimos trinta anos foi frustrada por um foco quase patológico na tecnologia e no aprendizado (mais especificamente, o potencial da tecnologia para 'habilitar', 'auxiliar', 'aprimorar' ou até mesmo ' transformar' o aprendizado). Isto é, os trabalhos estão enraizados nas "ciências da aprendizagem", "ciências pedagógicas" e "ciências do design". É claro que todas essas áreas são elementos centrais da "educação", como uma disciplina acadêmica aplicada. No entanto, o predomínio de tais preocupações nas discussões sobre escolas e tecnologias continua sendo altamente frustrante para os que são mais politicamente conscientes e/ou sociologicamente atentos (SELWYN et al., 2016, p. 148, tradução livre).

Entre suas implicações teóricas, a sociologia digital tem produzido efeitos particularmente sensíveis no plano conceitual. Durante parte significativa de sua história como objeto de estudo acadêmico, as tecnologias digitais e sua compreensão sofreram forte influência de formulações advindas de áreas técnicas como a engenharia, a informática e as ciências da computação. Essa configuração contribuiu para o predomínio de definições e caracterizações excessivamente centradas nas dimensões materiais e instrumentais da tecnologia. Sob essa 
ótica, não espanta que os principais operadores conceituais nesse campo se concentrem na descrição e análise de aparelhos (computadores, smartphones, consoles e TVs), de suas funções formais (acesso à informação, interação social, divertimento/distração) e, de acordo com o propósito da discussão, de seu potencial disruptivo no interior de um dado setor ou atividade (aumento de produtividade, automatização de tarefas, promoção de aprendizagens significativas).

Por outro lado, Selwyn (2011a) esclarece que definições com ênfase no binômio aparelho-funcionalidade não são adequadas para enfrentar a complexidade das apropriações sociais das tecnologias digitais. Como alternativa, introduz uma concepção favorável à incorporação tanto de aspectos técnicos quanto socioculturais das tecnologias, descrevendo-as em três dimensões distintas:

- $\quad$ Artefatos e dispositivos: as tecnologias em si e o(s) modo(s) como elas são projetadas e produzidas;

- $\quad$ Atividades e práticas: o que as pessoas fazem com as tecnologias, abrangendo questões de interação humana, organização, identidade e práticas culturais;

- Contextos: arranjos sociais e formas organizacionais que cercam o uso das tecnologias (incluindo instituições, estruturas sociais e culturas).

Trata-se de uma perspectiva multirrefencial que reconhece a agência de elementos humanos e não humanos na materialização das tecnologias e de seus desdobramentos em diferentes contextos de inserção. Nesse caso, a integração de tecnologias à educação/escola pode ser entendida como um esforço que extrapola a mera garantia de acesso a artefatos informáticos. Também não se completa com a posse das competências e dos conhecimentos necessários à utilização de softwares e hardwares diversos em situações didáticas. A esse conjunto passam a se somar fatores macro e mesoestruturais, como os tipos de participação institucional na promoção (ou restrição) de práticas e usos específicos das TDICs de acordo com seus objetivos e interesses, juntamente com a reflexão permanente sobre os demais fatores organizacionais e circunstanciais que regulam as condições de seleção, utilização e avaliação das mídias digitais. Esse raciocínio sugere que a viabilidade das propostas de educação baseada em tecnologias depende não só de informações relativas ao acesso aos dispositivos digitais ou ao grau de alfabetização digital de professores e alunos. Esse prognóstico também necessita da compreensão acerca dos modelos de sociabilidade e protocolos comunitários/institucionais de conduta que condicionam a presença e o uso das tecnologias digitais, no sentido de explicitar 
seus discursos e valores subjacentes, além de desmistificar seu suposto caráter "espontâneo" e "natural".

\section{SOCIOLOGIA DIGITAL DA ESCOLA: POLITIZANDO AS TDICs NA EDUCAÇÃO}

A sociologia digital e sua vertente educacional mantêm um diálogo permanente no que diz respeito a seus princípios norteadores e linhas de ação. Partindo dessa interlocução, Selwyn et al. (2016) apresentam três proposições para orientar um trabalho sociológico mais sensível aos componentes políticos, econômicos e culturais das tecnologias nas escolas e nos demais contextos educativos. São elas:

1) Abordar o digital como um domínio inerentemente problemático;

2) Descrever as realidades cotidianas das escolas e tecnologias;

3) Expandir a imaginação metodológica.

O primeiro ponto diz respeito ao impulso de desafiar o que é dado como certo e desvelar as desigualdades e diferenças de poder associadas à presença (ou ausência) do digital nos espaços e tempos da educação. A sociologia digital se move por um estado insolúvel de insatisfação e desconforto em relação às coisas como são ou estão. Essa disposição consiste em alimentar um ceticismo ativo e comprometido com o entendimento do digital, não devendo ser confundido com a rejeição cínica e apática de problemáticas espinhosas. Selwyn et al. (2016) esclarecem que para revelar a complexidade entre educação e tecnologias devem ser observadas ao menos três dimensões dessa relação, a saber: 1) ideologia - partindo da natureza política da educação, dirige-se às questões ligadas à hegemonia e aos conflitos entre diferentes visões de mundo e projetos de sociedade, juntamente com os papéis delegados às instituições de ensino, aos professores, alunos e gestores no interior de cada uma dessas perspectivas; 2) experiência humana - reconhecendo que o uso de TDICs é uma atividade tão humana quanto tecnológica, essa faceta se volta aos sentimentos, aos significados, às emoções, aos (des)prazeres e às (in)sensibilidades que emergem do encontro entre pessoas e tecnologias no cotidiano de suas vidas e de sua escolarização; 3) contextos e estruturas sociais - dedica-se ao conjunto de fatores extraindividuais capazes de moldar ou influenciar as ações e os pensamentos humanos na relação com as tecnologias, servindo como terreno para a reprodução e a luta ideológica por via de estruturas organizacionais, juntamente com influências contextuais ligadas à classe, ao gênero, à raça e à etnia. Essas orientações facilitam o reconhecimento das mudanças desencadeadas pelo digital nas escolas, expandindo escopos de estudo e investigação para além 
de indagações corriqueiras como "o que funciona?" ou "e se...?”, as quais têm monopolizado o debate acadêmico sobre as tecnologias na educação ao longo das últimas décadas.

Deve-se ressaltar que a ideologia é um aspecto central da crítica sociológica contemporânea. Sua importância advém, em boa medida, da sua autoridade sobre domínios essenciais à interface entre educação e tecnologias, agindo tanto em nível micro, como a experiência humana, quanto macro, a exemplo das estruturas sociais e dos aparatos institucionais. Em Distrusting educational technology: critical questions for changing times (Desconfiando da tecnologia educacional: questões críticas para tempos de mudança), Selwyn (2013) desafia o clima de conformidade generalizado em torno de dispositivos pedagógicos em ascensão, como jogos de computador, ambientes virtuais (de aprendizagem), recursos educacionais abertos e mídias sociais. Para isso, num primeiro momento, revisita a noção de ideologia, dialogando com pensadores que contribuíram para a construção histórica do conceito: de Karl Marx a Zygmunt Bauman, passando por Antonio Gramsci, Jurgen Habermas, David Harvey e Ernesto Laclau. Nesse contexto, a ideologia não se restringiu ao papel de poder tirânico universal que constrange as crenças e o arbítrio das massas em favor de uma vontade dominante absoluta. Ampliando seu enquadramento, o trabalho delimitou uma concepção com contornos menos rígidos, na qual a ideologia representa a manipulação de entendimentos e a conquista do senso comum, com o objetivo de legitimar os interesses e as visões de mundo de grupos específicos. Partindo dessa descrição, o autor contextualiza as principais correntes ideológicas estabelecidas na sociedade contemporânea, como o neoliberalismo, o libertarianismo e a ideologia da "nova economia", apresentando sua conexão com discursos populares no campo das tecnologias educacionais. Dentre eles, sobressaem:

1) Aprendizagem centrada no aluno: sustentada em valores progressistas, correntes pedagógicas construtivistas e teorias do desenvolvimento sociointeracionistas, essa vertente aponta que as tecnologias digitais oferecem acesso a fontes inesgotáveis de informação/conhecimento, além de proporcionar espaços virtuais favoráveis à aprendizagem colaborativa e significativa, configurando-se como contextos educacionais inerentemente empoderadores e, portanto, melhores que os da educação tradicional - ainda que sejam escassos os estudos empíricos comparativos capazes de constatar a superioridade incondicional do digital em relação ao analógico;

2) A(s) eficiência(s) da educação: sob os slogans da "modernização" e da "racionalização", essa ideologia estabelece que as tecnologias digitais dispõem de recursos que 
aprimoram a performance da educação em âmbitos variados, como o acesso, a oferta, a (auto)avaliação, a transparência, a mensurabilidade e até mesmo a sua rentabilidade - visão fortemente enraizada em interesses pró-corporativos e mercantis que convivem com reiteradas acusações de promover discretamente variantes digitais do taylorismo;

3) Comunitarismo: com raízes no espírito da contracultura hippie e do Vale do Silício, sustenta-se na crença de que as tecnologias digitais têm reinventado e reorganizado diferentes aspectos da cultura e da sociedade a partir da oferta de recursos técnicos para a criação de comunidades globais baseadas na empatia e afinidade, abrindo caminhos para novas utopias e formas de resistência aos poderes hegemônicos - condição que também tem fortalecido associações problemáticas, como aquelas ligadas a grupos neonazistas, redes de pornografia infantil, teorias conspiratórias e cyberbullying;

4) Anti-institucionalismo: fortemente impulsionada pelo espírito de autoorganização e autodeterminação do comunitarismo, essa ideologia postula que as tecnologias oferecem meios de resistência contra a tecnocracia instaurada pelas classes dominantes, insinuando que a garantia de acesso a recursos e conhecimentos informáticos para todos os cidadãos é um ingrediente fundamental no fortalecimento das democracias e na luta contra o autoritarismo de instituições governamentais, burocráticas, militares e corporativas - ideia que também tem reavivado concepções educacionais controversas, a exemplo da desescolarização e do homeschooling;

5) Tecnofundamentalismo: apesar de raramente percebido, esse princípio é altamente difundido no imaginário social e consiste num misto de fé e encantamento concernidos na crença de que as tecnologias melhoram substancialmente todos aspectos da vida cotidiana e das relações sociais, dispondo de um potencial infinito de realização e transformação radical da realidade - ainda que essa perspectiva frequentemente culmine em simplificações solucionistas dos desafios do mundo social, os quais são reduzidos a meros problemas matemático-computacionais equacionáveis por meio de apps, plataformas e soluções algorítmicas.

A despeito de seu potencial analítico, a crítica ideológica está distante de constituir uma prática dominante no debate sobre educação e tecnologias. Selwyn (2013) associa o desinteresse pela política das tecnologias digitais a fatores como: a) a distância cada vez mais acentuada entre aqueles que projetam, desenvolvem, fabricam e comercializam novas tecnologias do restante da massa que apenas as consome/utiliza; b) a tendência longeva no 
pensamento ocidental de encarar as tecnologias digitais como ferramentas que estão apartadas da condição humana e que, por isso, podem ser usadas e descartadas a qualquer momento e sem quaisquer consequências pessoais em longo prazo; c) a crença de que as tecnologias digitais inauguram tempos e espaços inteiramente autônomos, nos quais as pessoas podem interagir e atuar, sem sofrer perturbações de suas existências off-line. Diante desses indícios, parece compreensível o estado de "sonambulismo" que acomete boa parte dos pesquisadores e comentadores acadêmicos em relação à faceta ideológica das TDICs, fazendo com que estas sejam encaradas principalmente por seus efeitos aprazíveis e benéficos, como um território capaz de transcender a quaisquer conflitos, interesses e preocupações da vida social (SELWYN, 2011b; SELWYN, 2013). Nesse contexto, o ato de "desconfiar" das tecnologias não significa rejeitá-las de forma compulsória e irrefletida. Na verdade, essa postura consiste em abordá-las como parte de um amplo complexo de modos pelos quais tensões sociais, econômicas e políticas são mediadas nos contextos educacionais, os quais, por sua vez, engajam-se nesses mesmos enfrentamentos a partir de formas supostamente neutras de aprender e ensinar.

A segunda proposição da sociologia digital para o estudo das tecnologias nas escolas está em consonância com essa demanda. A descrição e o questionamento das realidades cotidianas na sociedade digital atuam como meios para observar as conexões entre problemas privados e preocupações públicas. Selwyn et al. (2016) esclarecem que, além de alterar os modos de produção e comunicação do conhecimento e da aprendizagem, as tecnologias agem sobre elementos centrais da educação, corroborando práticas, alfabetismos e "modos de fazer" que até então podem não ter sido suficientemente examinados (ou sequer identificados). Tratase de uma caracterização que estimula olhares atentos a temas caros à política das escolas contemporâneas, tais como: a administração e governança das escolas; o trabalho digital nas escolas e na escolarização; e a vigilância pós-panóptica escolar. No geral, a sociologia digital interpela os temas nesse domínio sabendo que

[...] as tecnologias digitais claramente mediam as relações e hierarquias sociais no interior da escola. Como tal, as tecnologias digitais precisam ser vistas como um local essencial para formas variadas de trabalho identitário, tanto por jovens quanto por adultos. As tecnologias digitais também são um foco das lutas contínuas entre instituições e indivíduos - replicando e reforçando as tensões entre estrutura e agência, regulação e resistência. Em termos de tempo e espaço, as tecnologias digitais obscurecem as fronteiras entre 'escola', 'casa' e outras instituições e configurações sociais. Mais prosaicamente, talvez, as tecnologias digitais estejam associadas à materialidade em constante mudança e às "coisas" das escolas - o ambiente 
físico, os objetos materiais dentro dele, os arranjos espaciais que continuam a constituir a escola ou a sala de aula como um "local" (SELWYN et al., 2016, p. 152, tradução livre).

A política econômica das instituições escolares apresenta potencial heurístico ímpar para a sociologia digital. Nesse âmbito costumam ocorrer observações acerca das escolas como objeto de interesse comercial, mais especificamente, sobre as tecnologias educacionais como nicho de mercado altamente disputado e em que são fabricados tanto recursos didáticopedagógicos smart, quanto discursos dirigidos a pais, professores, gestores, acadêmicos e governos sobre o presente e o futuro da educação. Sob o argumento de contribuir para a modernização da instituição escolar por meio de upgrades técnicos, CEOs, empresas de tecnologias, organizações não governamentais, sejam elas independentes ou patrocinadas por setores da indústria, têm disseminado a crença de que reconstruir os alicerces da educação é uma tarefa inevitável para a melhoria da qualidade e eficiência dos sistemas de ensino. Tratase de um enunciado que, apesar de plausível, frequentemente atua como camuflagem para a promoção de valores e interesses privados no seio da educação pública, sob a roupagem de ajustes e incrementos puramente técnicos e, como tais, aparentemente isentos de inclinações ideológicas.

Tomemos, por exemplo, como a tecnologia e o imperativo imaginado do 'digital' estão sendo usados como justificativa para redesenhar, reformar e reorientar a natureza, a forma e os valores da escola pública. Fundações filantrópicas, empresas transnacionais, capitalistas de risco e outros "edupreendedores" continuam investindo quantidades substanciais de tempo, financiando e gerando tentativas de "consertar" e/ou "perturbar" nossos sistemas escolares supostamente "quebrados" por meio de abordagens baseadas em tecnologia. Isso inclui promessas de "personalização orientada pela tecnologia", aprendizado baseado em jogos, "sala de aula invertida", cultura maker, "competências do século XXI" e assim por diante. Isso também inclui projetos para a escolarização nas linhas da Altschool, Quest-to-Learn, $P-T E C H$ e até mesmo "Steven Jobs Schools". Reversões e inovações como essas podem muito bem ser desejáveis e benéficas, mas certamente exigem escrutínio e crítica fundamentada. Muitas das "novas" formas de educação digital promovidas por interesses comerciais baseiam-se, sem dúvida, em agendas e ideologias diferentes das que estamos acostumados a ver na educação pública. Essas mudanças na ênfase do tom podem ou não ser uma "coisa boa". No entanto, essas são questões que exigem mais reconhecimento, debate e averiguação de dentro do establishment educacional (SELWYN et al., 2016, p. 152-153, tradução livre).

O reconhecimento da política como elemento intercessor nas relações entre educação e tecnologias favorece a pluralização das pautas no bojo da sociologia digital. Sobre isso, Selwyn 
e Facer (2013) ajudam a visualizar esse campo temático, destacando frentes como: 1) os discursos e propósitos da educação nos quais são inscritas as tecnologias educacionais; 2) as definições dos problemas para os quais as TDICs são invocadas como solução; 3) os processos políticos instáveis e contestados pelos quais as "tecnologias" são projetadas, introduzidas e apropriadas na educação; 4) as realidades conflituosas da prática concreta com as tecnologias educacionais nas instituições contemporâneas; 5) a economia política do campo da tecnologia educacional e suas implicações para a justiça social; 6) a abertura de novos espaços de debate com uma ampla gama de atores sociais sobre as práticas e políticas da tecnologia educacional. Os autores advertem ainda que a defesa de um dado enquadramento crítico das tecnologias educacionais não deve alimentar a crença arrogante na superioridade de uma abordagem intelectual específica em relação às demais. Um dos principais desafios nesse horizonte é justamente distinguir e explorar dimensões adicionais do estudo das tecnologias na educação, oferecendo leituras complementares àquelas realizadas pelas vertentes inscritas nas já mencionadas ciências do ensino e da aprendizagem.

O terceiro e último apontamento da sociologia digital para o estudo das escolas chama atenção para o desafio relativo aos instrumentos e técnicas de pesquisa. O apelo à ampliação da imaginação metodológica vem ao encontro do anseio de (re)conciliação entre o trabalho acadêmico e a vida social permeada por softwares, dispositivos de comunicação ubíqua e plataformas on-line de sociabilidade. Em meio ao cenário de mudança, Selwyn et al. (2016) apontam o surgimento de novas maneiras de abordar os problemas e contextos digitais. Um dos exemplos diz respeito ao conjunto de ferramentas e estratégias reunidas sob a denominação de ciências sociais computacionais. Diante da crescente massa de dados resultantes da aplicação de tecnologias em múltiplos contextos e situações escolares, entram em cena novas possibilidades de modelagem, simulação e análise dos fenômenos afetos à educação. Trata-se de uma alternativa cuja importância se eleva à medida que se afirmam preocupações de natureza estatística no âmbito de sistemas ensino nacionais e distritais, paralelamente ao estabelecimento de políticas de transparência e de acesso aberto aos dados educacionais.

O digital também está implicado na emergência de complexos temáticos interessados na dimensão simbólica das TDICs. Mais do que uma fonte abundante de dados ainda pouco explorados, ou um arcabouço prenhe de ferramentas de pesquisa baseadas em software, o digital constitui um número crescente de mundos vividos que, apesar de dotados de nuances e autonomia, mantêm canais de comunicação com os demais campos de experiência da vida off- 
line. À primeira vista, essa descrição se mostra compatível com a paulatina desterritorialização dos espaços educativos, cujos efeitos se materializam na popularização de diversos ambientes virtuais de ensino e aprendizagem, processo intimamente associado ao fortalecimento de modalidades de ensino híbrido ou inteiramente baseadas em espaços digitais. Do mesmo modo, multiplicam-se os olhares interessados em compreender os contextos formativos digitais não institucionais, cuja informalidade tem ajudado a constituir comunidades de aprendizagem que estão em atrito permanente com as atividades desenvolvidas dentro das escolas e universidades.

A intensificação do debate sobre abordagens qualitativas de pesquisa voltadas às problemáticas do digital é, em certo sentido, sintomática em relação à legitimação das práticas socioculturais sustentadas por tecnologias como objetos dignos do interesse acadêmico. Blogs, plataformas de streaming, games on-line de mundos massivos e mídias sociais são apenas alguns dos territórios que abrigam corpos sociais sustentados por vínculos de pertencimento e sociabilidades singulares. Para cada um deles, táticas e métodos específicos de imersão e análise são colocados em prática, acionando desde técnicas tradicionais, como a análise de discurso, a abordagens substancialmente reformuladas, como é a netnografia (BOELLSTORFF et al., 2012; MARRES, 2016; SELWYN, 2019). Por essa razão, a sociologia digital (da escola) é considerada um empreendimento que exige tanto disposição crítica, quanto abertura criativa à invenção e experimentação de fórmulas e combinações capazes de retratar sistematicamente as singularidades das experiências socioformativas fomentadas pelas TDICs.

\section{CONSIDERAÇÕES FINAIS}

Este ensaio buscou contribuir para o amadurecimento da crítica das relações entre educação e tecnologias, a partir do diálogo com os trabalhos de Neil Selwyn. Mais uma vez, ressalta-se que não houve a intenção de sumarizar a obra do autor, dados os limites impostos ao presente texto, bem como a extensão considerável da produção do acadêmico em evidência.

Para além de ferramentas pedagógicas e aparelhos utilizados para "melhorar" a educação, as tecnologias digitais representam um campo de produção e circulação discursiva. Trata-se de um terreno prenhe de noções, à primeira vista, virtuosas, dentre as quais sobressaem ideias como "transformação", "inovação", "disrupção", “aprimoramento", "renovação", "racionalização" e "modernização". Presente nos principais relatos sobre as tecnologias na educação, esse vocabulário tem ajudado a consolidar narrativas refratárias à suspeita, fortalecendo visões platônicas e simplórias do digital. Essa tendência tem sua expressão mais 
pungente no determinismo tecnológico, isto é, no pressuposto de que as tecnologias constituem uma esfera autônoma e que, portanto, são capazes de produzir impactos previsíveis na realidade, independentemente de quaisquer fatores sociais, culturais e institucionais. Geralmente, os discursos relacionados às tecnologias educacionais estão alicerçados em diagnósticos de como a educação contemporânea "é", juntamente com projeções de como ela "deveria ser", constituindo-se em descrições que frequentemente ignoram tanto a pluralidade das explicações para as crises educacionais do presente, quanto o caráter aberto e contestado do futuro. Ao fazer isso, o digital se traveste de entidade apolítica, encobrindo suas feições ideológicas ao dissimular sua participação por vezes decisiva em tensões e disputas de poder.

Nesse contexto, a sociologia digital emerge como disciplina voltada à compreensão sistemática da sociedade em rede. Para isso, redimensiona seus escopos temáticos e metodológicos para além de preocupações utilitaristas, desviando seu foco das tecnicidades e das especulações sobre usos promissores das TDICs. Já em sua vertente voltada à problemática escolar, tenta equacionar tanto o baixo interesse da sociologia da educação em relação ao digital, quanto a lacuna crítica demonstrada pela maioria dos estudos sobre os novos meios. Seu propósito é desmistificar a abordagem hegemônica das tecnologias na educação, delimitando o digital como agente implicado em estruturas de dominação e hierarquias, a partir da descrição de cotidianos, experiências sociais, protocolos organizacionais e configurações institucionais.

Por fim, o diálogo com a obra de Neil Selwyn mostrou-se fecundo, na medida em que favoreceu o aprofundamento do debate a partir do que vem sendo dito e pensado sobre as tecnologias digitais no campo educacional. Espera-se que o presente trabalho possa dar visibilidade às ideias do autor, bem como sensibilizar a comunidade acadêmica e educacional para a urgência no fomento de enfoques multidimensionais e na superação de dogmatismos em relação à cultura digital e suas implicações para as instituições e os processos formativos.

\section{REFERÊNCIAS}

BOELLSTORF, Tom et al. Etnography and virtual worlds: a handbook of method. New Jersey: Princeton Press, 2012.

BUCKINGHAM, David. Precisamos realmente de uma educação para os meios?

Comunicação \& Educação, São Paulo, ano XVII, n. 2, jun/dez, p. 41-60, 2012.

MARRES, Noortje. Digital Sociology. Malden, MA: Polity, 2017. 
MOROZOV, Evgeny. To save everything, click here: the folly of technological solutionism. New York: Publicaffairs Books, 2013.

SELWYN, Neil. Uso das TIC na Educação e a promoção de inclusão social: uma perspectiva crítica do reino unido. Campinas, Educação \& Sociedade, vol. 29, n. 104, p. 815-850, 2008.

SELWYN, Neil. Education and technology: key issues and debates. New York: Continuum, 2011a.

SELWYN, Neil. Schools and schooling in digital age: a critical analysis. New York: Routledge, 2011b.

SELWYN, Neil. Distrusting Educational Technology. London: Routledge, 2013.

SELWYN, Neil. Is technology good for education? Cambridge: Polity Press, 2016.

SELWYN, Neil. Educação e tecnologia: questões críticas. In: FERREIRA, Gisele Martins dos Santos; ROSADO, Luis Alexande da Silva; CARVALHO, Jaciara de Sá. Educação e Tecnologias: abordagens críticas. Rio de Janeiro: SESES, 2017. p. 85-102.

SELWYN, Neil. What is Digital Sociology. Cambridge, UK: Polity, 2019.

SELWYN, Neil et al. Toward a digital sociology of school. In: DANIELS, Jessie; GREGORY, Karen; MCMILLAN COTTOM, Tessie (Orgs.). Digital sociologies. Bristol: Policy Press, 2016. p. 147-162.

SELWYN, Neil; FACER, Keri. Introduction: the need for a politics of education and technology. In: SELWYN, Neil; FACER, Keri. The politics of education and technology: conflicts, controversies, and connections. New York: Palgrave Mcmillian, 2013. p. 101-125.

SIBILIA, Paula. A escola no mundo hiperconectado: redes em vez de muros? Matrizes, São Paulo, v. 5, n. 2, p. 195-211, 2012.

\section{NOTAS}

${ }^{1}$ Para maiores detalhes, consultar: https://research.monash.edu/en/persons/neil-selwyn.

${ }^{2}$ Massive Open Online Courses ("cursos on-line abertos e massivos").

${ }^{3}$ Nessa ocasião, cita referências clássicas na sociologia, como Karl Marx, Emilé Durkheim e Max Weber.

${ }^{4}$ Trata-se de um termo genérico que abrange as transformações na organização e nas relações capitalistas contemporâneas, dentre as quais se destacam aquelas que se associam a noções como o "pós-fordismo", a "economia do conhecimento" e a "sociedade da informação".

Recebido em: 10/03/2020

Aprovado em: 13/06/2020 